\title{
Evaluation on the Sustainable Development of County in the Hilly Area of Northwest Sichuan from the Perspective of Niche
}

\author{
Linping Huang ${ }^{1}$, Chunlong $\mathrm{Cui}^{1,2}$, Qi Cao ${ }^{1}$, Minghong $\mathbf{Y u}^{1}$ \\ ${ }^{1}$ Department of Civil and Architectural Engineering, Southwest University of Science and Technology, \\ Mianyang, Sichuan 621010 \\ ${ }^{2}$ Institute of Land and Resources Utilization, Southwest University of Science and Technology, Mianyang, \\ Sichuan 621010
}

Keywords: Mianyang City; Niche; sustainable development; index system

\begin{abstract}
The construction of sustainable development system is an important basis for the scientific evaluation of coordinated development of urban economic, social and environmental conditions. Mianyang (2 District 6 County 1 city) is the representative of hilly northwestern county town in the underdeveloped level. Through the construction of niche suitability model, the sustainable development evaluation system of 18 indicators of the three subsystems of economy, society and environment is established, and comprehensive evaluation of ecologically sustainable and coordinated development of counties in Mianyang is conducted. The results show that the economic niche is the best in the central plain area, and the ecological niche is the best in hilly and mountainous areas, while the comprehensive niche of the Fucheng and Jiangyou cities is higher than that of other counties. The suitability level of the comprehensive niche has been growing gradually. Based on the comparison of time and space evolution of the three systems and the comprehensive niche suitability of each county town, this paper tries to put forward suggestions to promote the coordinated development of the county towns.
\end{abstract}

\section{Introduction}

City is the most concentrated area of human activity. County-level regions account for more than $90 \%$ of the total area in China [1]. City niche fitness is a major indicator, which represents the conformance level of the real niche and the best niche, reflecting the harmony degree of urban ecosystem, the strength of urban competitiveness and the ability of sustainable development.

At present, the rapidly developing cities are paid more attention currently, while the underdeveloped urban agglomerations in county-level are less concerned. Especially the county region towns in the hilly grounds of western mountains. This paper aims to provide a theoretical basis for the strategy and system of city's sustainable development.

\section{Study Area and Pretreatment of Data Source}

Mianyang City is located in the hilly area of northwestern Sichuan with the total land area of 20,248.4 square kilometers, covering from 31 degrees 16 minutes to 31 degrees 48 minutes of north latitude, and from 104 degrees 29 minutes to 104 degrees 50 minutes of east longitude [2]. The topography of Mianyang slopes from northwest to southeast. The western part of this city is a transitional zone from the Qinghai-Tibet Plateau to the Sichuan Basin; the southeastern part is hilly regions of Sichuan Basin, with rolling hills accounting for about 75\% of the area [3].

The statistics of the proposed indicator system come from "Statistical Yearbook of Mianyang from 2012 to 2016", which includes statistics of Mianyang from 2011 to 2015. According to the niche fitness theory, the suitability of regional habitat condition is measured by the regional niche fitness, and the ecological niche fitness of economic, social and environmental subsystems as well as the comprehensive ecological niche fitness are selected as evaluation indicators which are screening and normalized later. 


\section{Research Method}

Aiming at the 3 districts, 5 counties and 1 city in Mianyang City, a specific indicator system of sustainable development evaluation in the county region is constructed in this study. After factor analysis and principal component screening of the related indicators, social and environmental subsystems are obtained, besides, the county normalization is carried out.

The standardized values of ecological indicators needed for the development are recorded as X1, X2.....Xn [4-5]. Appropriate amendments are made based on the summary of the previous studies, and the calculation model of urban niche fitness is determined as equation (1):

$$
F_{i}=\sum_{j=1}^{m} \beta_{j} \frac{\min \left\{\left|x_{i j}-x_{a j}\right|\right\}+\frac{1}{2} \times \max \left\{\left|x_{i j}-x_{a j}\right|\right\}}{\left|x_{i j}-x_{a j}\right|+\frac{1}{2} \times \max \left\{\left|x_{i j}-x_{a j}\right|\right\}}
$$

In addition, the comprehensive niche fitness is calculated by the niche fitness and corresponding weight of each indicator.

\subsection{Calculation indicator and niche fitness model}

The weight and the optimal niche of each ecological factor $\beta \mathrm{j}$ are determined with AHP [6], the weight of niche fitness for each factor is determined by the entropy weight method. Related indicators and the weight are shown in Table 1.

Table 1 Indicator weight

\begin{tabular}{|c|c|c|}
\hline $\begin{array}{l}\text { Assessment } \\
\text { factor( } \beta \mathrm{i})\end{array}$ & Single indicator & $\begin{array}{c}\text { Weight of } \\
\text { ecological } \\
\text { factor }\end{array}$ \\
\hline \multirow{6}{*}{$\begin{array}{c}\text { Economic } \\
\text { development } \\
\text { level } \\
0.4013\end{array}$} & Per capita GDP (RMB yuan) & 0.2590 \\
\hline & Average salary of employed persons (RMB yuan) & 0.1010 \\
\hline & $\begin{array}{l}\text { Non-public economic added value (RMB ten } \\
\text { thousand vuan) }\end{array}$ & 0.2332 \\
\hline & Per capita fixed asset investment (RMB yuan) & 0.2476 \\
\hline & Per capita financial income (RMB yuan) & 0.1182 \\
\hline & Per capita financial expenditure (RMB yuan) & 0.0410 \\
\hline \multirow{6}{*}{$\begin{array}{c}\text { Social } \\
\text { living } \\
\text { level } \\
0.1678\end{array}$} & $\begin{array}{l}\text { Household electricity consumption (ten thousand } \\
\text { kwh) }\end{array}$ & 0.1342 \\
\hline & Number of Social Welfare Adoption Units (unit) & 0.0980 \\
\hline & Number of health care institutions (unit) & 0.2498 \\
\hline & Population density (person/ $\mathrm{km}^{2}$ ) & 0.1821 \\
\hline & Internet users (household) & 0.2279 \\
\hline & $\begin{array}{l}\text { Number of new rural cooperative medical insurance } \\
\text { (person) }\end{array}$ & 0.2080 \\
\hline \multirow{6}{*}{$\begin{array}{c}\text { Resources } \\
\text { and } \\
\text { environment } \\
\text { level } \\
0.2893\end{array}$} & Forest area (hectare) & 0.0420 \\
\hline & Sulfur dioxide emissions (tons) & 0.2780 \\
\hline & Nitrogen oxide emissions (tons) & 0.2972 \\
\hline & Smoke (powder) dust emissions (tons) & 0.2618 \\
\hline & Number of sewage treatment plant (unit) & 0.0456 \\
\hline & Annual rainfall (mm) & 0.0753 \\
\hline
\end{tabular}

\subsection{Spatial Autocorrelation Analysis}

Spatial autocorrelation analysis of GIS can be used to fundamentally improve the statistical analysis, and measure the spatial difference and pattern evolution between urban niches. In this paper, local spatial autocorrelation of niche fitness is analyzed with Getis-Ord G* [7]. 


\section{Results and Analysis}

Table 1 shows the weight of sustainable development indicators. The dominant indicators affecting economic niche fitness are GDP per capita; the dominant indicators affecting social niche fitness are household electricity consumption and population density; the dominant indicators affecting environmental niche fitness are sulfur dioxide emissions and smoke (powder) dust emission.

\subsection{Temporal analysis of urban niche fitness}

(1) From the perspective of time, as shown in Figure 1. The environmental niche fitness obviously fluctuates over time; economic niche fitness of Jiangyou has significantly increased; social niche fitness and environmental niche fitness of Fuchen district have significantly increased. Part of the reasons for this situation is that during the expansion process of the city.

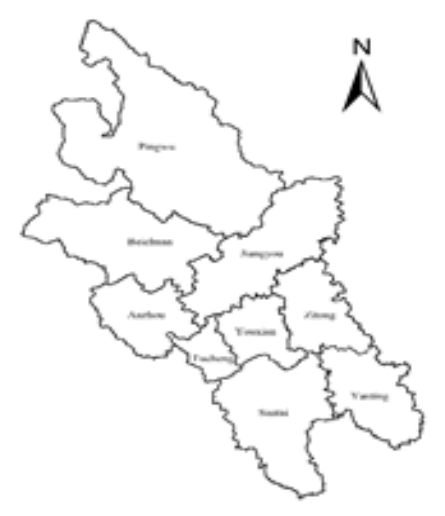

Fig.1 Administrative divisions of Mianyang City

(2) From the perspective of space, the distribution characteristics of niche fitness of urban sustainable development are analyzed, as shown in Figure 1. For economic and social niche fitness, cities in central plain area are obviously with a higher one, the southeast hilly areas are in the middle, northwest mountain area is with a lower one, Beichuan is weaker than Pingwu.

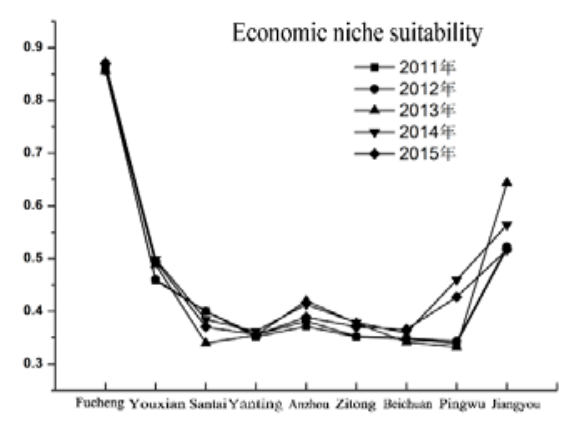

Fig.2 Economic niche suitability of Mianyang City, district and county in 2011-2015

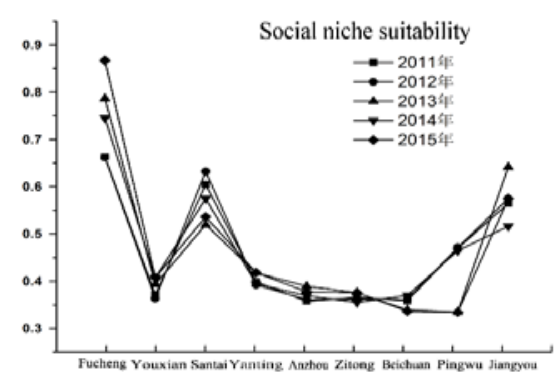

Fig.3 Social niche suitability of Mianyang City, district and county in 2011-2015 


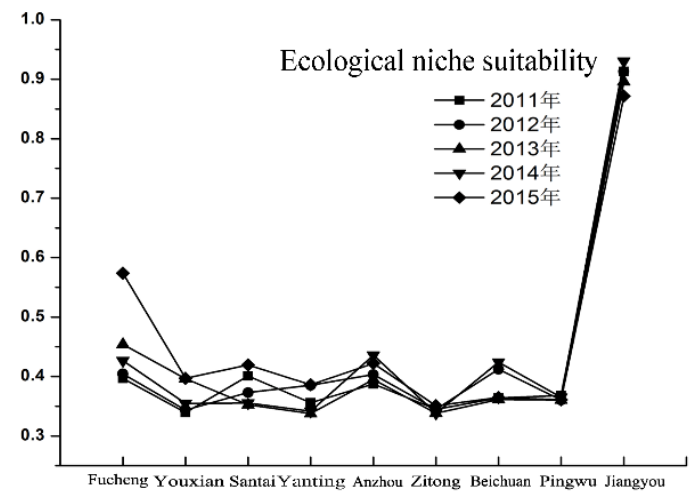

Fig.4 Ecological niche suitability of Mianyang City, district and county in 2011-2015

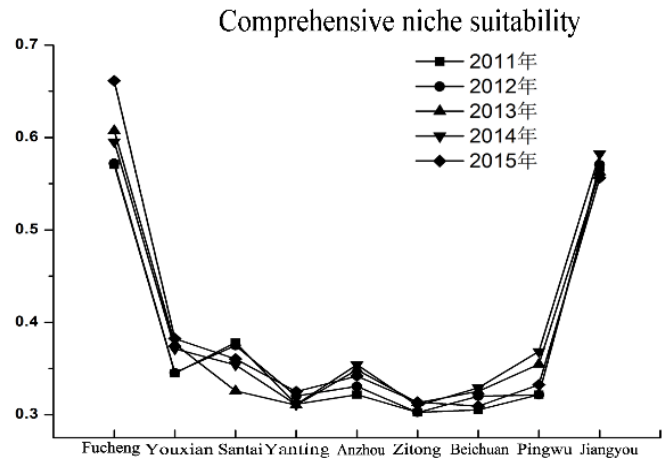

Fig.5 Comprehensive niche suitability of Mianyang City, district and county in 2011-2015

\subsection{Spatial pattern evolution of urban niche fitness}

As shown in Fig. 6 to Fig. 8, the hot spots of the comprehensive niche fitness are clustered in the central plains, and the cold spots are mainly distributed in the southeast hilly areas and the northwest mountainous areas with relatively backward economy and low living environment. Cold spots decreased year by year, with a transformation to the sub-cold zone and sub-hot zone. Comparing the spatial association pattern of comprehensive niche fitness, it is clear that the comprehensive development level of county region towns in Mianyang is gradually increasing.

\section{Suggestions on Sustainable Development of Hilly counties in Norwestern Sichuan}

Based on the above conclusions, two suggestions are proposed for the sustainable development of Mianyang county regions:

(1) The economic niche fitness in the central plain area is better, the environmental niche fitness in the hilly and mountainous area is better, the social niche fitness of all county region towns is in the similar level. Therefore, the same city construction of Mian (Fucheng and Youxian District) to Jiang (Jiangyou City) to an (Anzhou District) to Bei (Chuan) should be fully utilized, establish an interregional cooperation mechanism in the hilly area of northwest Sichuan, and promote the interdependent, mutual integrated and complementary cooperation, achieving the common development of the county region towns.

(2) Santai, Zitong, Yanting, Pingwu and Beichuan County are located in the hilly and mountainous area far away from the center of Mianyang City. Although the polarization effect of their growth pole cannot be exerted, each of them has own featured resources and superior environmental ecological factor. As a result, their similarities in natural resource, transport and location condition should be combined, and the common featured resource should be regionally co-ordinated planned and integrated. In this way, the disorder competition among counties can be suppressed, and the comprehensive competence of county region towns can be improved. 


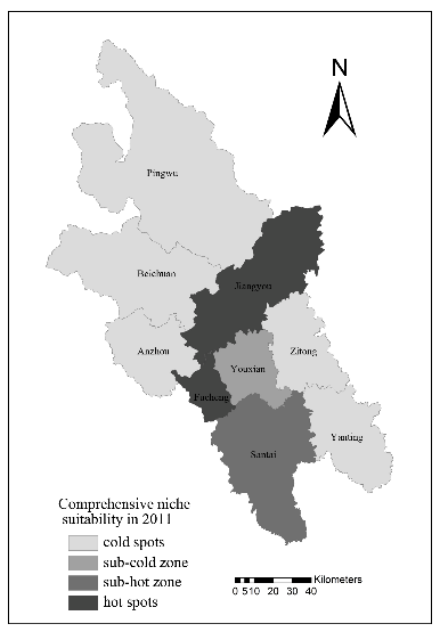

Fig.6 Comprehensive niche Spatial association pattern of Mianyang City, district and county in 2011

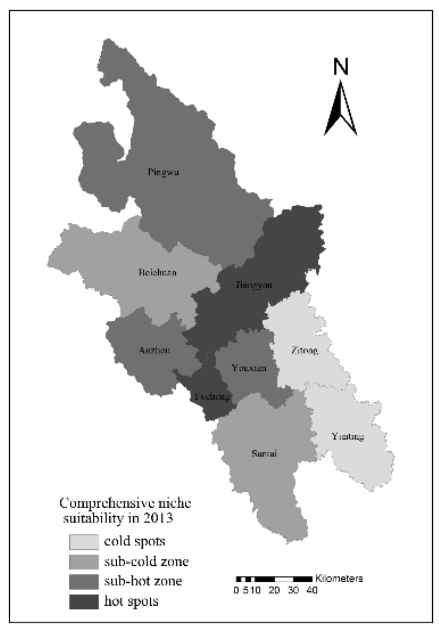

Fig.7 Comprehensive niche Spatial association pattern of Mianyang City, district and county in 2013

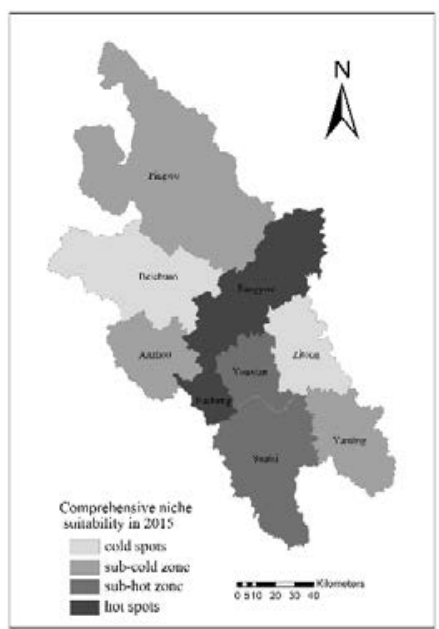

Fig.8 Comprehensive niche Spatial association pattern of Mianyang City, district and county in 2015

\section{Conclusion}

This paper analyzes the spatial and temporal evolution of the niche in west Sichuan hilly 
counties and finds out the problems existing in the urban development, a case study of Mianyang City. For each city, reasonable and phased plan and implementation should be completed according to its own characteristics and advantages, achieving a coordinated and sustainable development of economy, society and ecology. Urban economic development and social progress must be based on a good ecological environment, and the laws and regulations related to sustainable development are necessary to be strengthened.

\section{References}

[1] Wang Lili. Comparative analysis of urban niche fitness - A case study of 13 cities in Jiangsu Province [J]. New Urban Studies, 2007(3): 73-80.

[2] GAO Zhengfa. Commodity and geographical division of amphibians and reptiles in Mianyang, Sichuan [J]. Chinese Animal, 2006, 25(2): 317-319

[3] He Lintai. Urban design combined with the natural landscape situation - A case study of Mianyang [D]. Xi'an University of Architecture and Technology, 2006.

[4] Wang Lili. Comparative analysis of urban niche fitness - A case study of 13 cities in Jiangsu Province [J]. New Urban Studies, 2007(3): 73-80.

[5] Guo Yanqing, Yao Yuan, Xu Jinghong. Innovative ecosystem assessment model based on niche fitness [J]. Statistics and Decision, 2015(15): 13-16.

[6] Huang Linghua, Wei Guoyan. Application of PCA and AHP combination method in the sustainable development assessment of cities [J]. Statistics and Decision, 2007(15): 149-150.

[7] Xia Yu, Lin Aiwen, Zhu Hongji. Spatial pattern evolution of urban human settlements environmental suitability in the Yangtze River Delta [J]. Chinese Journal of Ecology, 2017, 32(2): 112-117. 